Original Article

\title{
Comparison of gait before and after superficial trunk muscle exercise and deep trunk muscle exercise
}

\author{
Hwanhee Kim, PhD, $\mathrm{OT}^{1)}$, Jemyung Shim, PhD, $\mathrm{PT}^{2 *}$, Minho Baek, $\mathrm{PhD}^{3)}$ \\ 1) Department of Physical Therapy, Semyung University, Republic of Korea \\ 2) Department of Physical Therapy, College of Health and Science, Kangwon National University: 346 \\ Hwangjo-ri, Dogye-eup, Samcheok-si, Gangwon-do 245-905, Republic of Korea \\ 3) Department of Fire and Disaster Prevention, College of Engineering, Kangwon National University, \\ Republic of Korea
}

\begin{abstract}
Purpose] The purpose of this study was to examine the effects of superficial trunk muscle and deep trunk muscle exercise on gait. [Subjects] The subjects were 45 young adults who voluntarily consented to participate. The subjects were divided into a control group, a superficial muscle exercise group, and a deep muscle exercise group with 15 participants in each group. [Methods] Each group performed the exercises 5 times a week for 4 weeks. A Gait Analyzer was used to measure the subjects' gait. A one-way ANOVA was conducted for analysis between each group. [Results] After 4 weeks, the values from right heel contact to foot flat, left foot flat to heel off, right foot flat to heel off, and left heel off to toe off significantly differed among the groups. [Conclusion] The superficial trunk muscle exercise improved stability, such as the period of mid stance during gait. The deep trunk muscle exercise improved mobility, such as heel contact to foot flat and heel off to toe off during gait.

Key words: Superficial trunk muscle exercise, Deep trunk muscle exercise, Gait
\end{abstract}

(This article was submitted Jul. 1, 2015, and was accepted Aug. 19, 2015)

\section{INTRODUCTION}

Human beings' trunk muscles are where all the forces and motility of the body occur. These muscles maintain balance when the body is moved, maintain appropriate musculoskeletal structure, and protect the muscles and bones ${ }^{1)}$.

Trunk muscles include the superficial trunk muscles, which are the body's lateral muscles, and the deep trunk muscles, which are the body's medial muscles ${ }^{2}$. The superficial trunk muscles consist of the rectus abdominis, internal oblique, external oblique, lateral quadratus lumborum, iliopsoas, and erector spinae. The deep trunk muscles are the transversus abdominis, multifidus, quadratus lumborum, and the rotator muscles.

Muscles located in the deep parts of the trunk increase trunk stability, maintain spinal posture, engage in respiration, adjust unconscious movements, and maintain proper posture $^{3-5)}$. While the superficial trunk muscles also aid in trunk stability, they are located on the lateral sides of the body and they mostly respond to strong forces or outside forces $^{2)}$.

*Corresponding author. Jemyung Shim (E-mail: sjm7897@ hanmail.net)

(C2015 The Society of Physical Therapy Science. Published by IPEC Inc. This is an open-access article distributed under the terms of the Creative Commons Attribution Non-Commercial No Derivatives (by-ncnd) License $<$ http://creativecommons.org/licenses/by-nc-nd/3.0/>.
These groups of trunk muscles affect different functions, such as balance, gait, foot pressure, breathing, and proprioception $^{5-8)}$. This study examines the effects of superficial and deep trunk muscle exercise on gait.

\section{SUBJECTS AND METHODS}

The subjects were 45 young adults who voluntarily consented to participate in this study and had no congenital deformities, orthopedic disorders, or any problems with walking. Before beginning the study, it was approved by Kangwon National University. This study followed the guidelines of the Declaration of Helsinki. The subjects were divided into a control group (CG), a superficial muscle exercise group (SMEG), and a deep muscle exercise group (DMEG), with 15 participants in each group. The average age, height, and weight of the CG were 21.9 years, $169.7 \mathrm{~cm}$, and $63.4 \mathrm{~kg}$, respectively. The average age, height, and weight of the SMEG were 22.2 years, $170.5 \mathrm{~cm}$, and $78.1 \mathrm{~kg}$, respectively. The average age, height, and weight of the DMEG were 21.3 years, $170.1 \mathrm{~cm}$, and $69.0 \mathrm{~kg}$, respectively.

A Gait Analyzer (Tech Storm Inc., Korea) ${ }^{9}$ ) was used to measure the subjects' gait. All subjects rested for 30 minutes in the laboratory before measurement of gait. Gait was measured three times. The mean values were calculated for the analysis. In each group, measurements were taken prior to the intervention and again at the end of the 4 weeks of intervention. The gait analyzer system analyzes foot length $(\mathrm{cm})$, foot width $(\mathrm{cm})$, toe angle $\left(^{\circ}\right)$, and step length $(\mathrm{mm})$. 
Table 1. Comparison of gait and feet before and after superficial muscle exercises and deep muscle exercises.

\begin{tabular}{|c|c|c|c|c|c|c|}
\hline & & & CG & SMEG & DMEG & \\
\hline \multirow{4}{*}{$\begin{array}{l}\text { Length } \\
(\mathrm{cm})\end{array}$} & \multirow{2}{*}{ Left } & Before & $25.14 \pm 1.56$ & $25.29 \pm 2.06$ & $25.37 \pm 2.13$ & \\
\hline & & After & $25.11 \pm 1.09$ & $25.56 \pm 2.12$ & $25.48 \pm 2.26$ & \\
\hline & \multirow{2}{*}{ Right } & Before & $25.48 \pm 1.38$ & $25.57 \pm 2.22$ & $25.37 \pm 2.13$ & \\
\hline & & After & $25.24 \pm 1.31$ & $25.23 \pm 2.84$ & $25.25 \pm 2.04$ & \\
\hline \multirow{4}{*}{$\begin{array}{l}\text { Width } \\
(\mathrm{cm})\end{array}$} & \multirow{2}{*}{ Left } & Before & $8.43 \pm 0.61$ & $8.97 \pm 1.01$ & $8.49 \pm 0.82$ & \\
\hline & & After & $8.30 \pm 0.76$ & $8.50 \pm 0.97$ & $8.35 \pm 1.08$ & \\
\hline & \multirow{2}{*}{ Right } & Before & $8.50 \pm 0.89$ & $9.28 \pm 1.09$ & $8.49 \pm 0.82$ & \\
\hline & & After & $8.12 \pm 0.71$ & $8.89 \pm 0.93$ & $8.28 \pm 1.03$ & \\
\hline \multirow{4}{*}{$\begin{array}{l}\text { Toe angle } \\
\left({ }^{\circ}\right)\end{array}$} & \multirow{2}{*}{ Left } & Before & $3.72 \pm 6.67$ & $4.01 \pm 2.92$ & $4.17 \pm 3.03$ & \\
\hline & & After & $3.51 \pm 5.84$ & $5.50 \pm 5.09$ & $4.06 \pm 3.03$ & \\
\hline & \multirow{2}{*}{ Right } & Before & $5.28 \pm 6.12$ & $4.23 \pm 3.76$ & $4.17 \pm 3.03$ & \\
\hline & & After & $5.68 \pm 6.59$ & $4.76 \pm 3.55$ & $4.56 \pm 4.47$ & \\
\hline \multirow{2}{*}{$\begin{array}{l}\text { Step time } \\
(\mathrm{sec})\end{array}$} & & Before & $0.76 \pm 0.10$ & $0.78 \pm 0.12$ & $0.76 \pm 0.12$ & \\
\hline & & After & $0.78 \pm 0.12$ & $0.80 \pm 0.09$ & $0.77 \pm 0.08$ & \\
\hline \multirow{2}{*}{$\begin{array}{l}\text { Step length } \\
(\mathrm{mm})\end{array}$} & & Before & $624.00 \pm 32.28$ & $628.00 \pm 53.62$ & $635.60 \pm 60.47$ & \\
\hline & & After & $644.00 \pm 69.44$ & $628.00 \pm 48.83$ & $626.40 \pm 37.67$ & \\
\hline \multirow{4}{*}{$\begin{array}{l}\text { Heel contact-foot flat } \\
(\%)\end{array}$} & \multirow{2}{*}{ Left } & Before & $13.50 \pm 3.03$ & $13.30 \pm 6.60$ & $15.50 \pm 2.42$ & \\
\hline & & After & $14.30 \pm 4.42$ & $12.00 \pm 3.91$ & $14.50 \pm 4.67$ & \\
\hline & \multirow{2}{*}{ Right } & Before & $14.90 \pm 5.24$ & $15.50 \pm 5.38$ & $15.50 \pm 2.42$ & \\
\hline & & After & $13.60 \pm 4.74$ & $12.56 \pm 4.09$ & $17.40 \pm 3.53$ & * \\
\hline \multirow{4}{*}{$\begin{array}{l}\text { Foot flat-heel off } \\
(\%)\end{array}$} & \multirow{2}{*}{ Left } & Before & $46.10 \pm 12.12$ & $51.60 \pm 10.94$ & $43.70 \pm 11.70$ & \\
\hline & & After & $45.90 \pm 12.66$ & $51.44 \pm 11.38$ & $38.80 \pm 10.69$ & $*$ \\
\hline & \multirow{2}{*}{ Right } & Before & $45.70 \pm 10.63$ & $47.40 \pm 9.05$ & $41.70 \pm 11.70$ & \\
\hline & & After & $46.10 \pm 18.38$ & $51.78 \pm 6.39$ & $38.40 \pm 9.44$ & $*$ \\
\hline \multirow{4}{*}{$\begin{array}{l}\text { Heel off-toe off } \\
(\%)\end{array}$} & \multirow{2}{*}{ Left } & Before & $40.60 \pm 10.12$ & $38.10 \pm 8.65$ & $41.80 \pm 9.72$ & \\
\hline & & After & $39.80 \pm 9.58$ & $36.56 \pm 9.38$ & $46.90 \pm 7.82$ & * \\
\hline & \multirow{2}{*}{ Right } & Before & $39.40 \pm 7.76$ & $37.10 \pm 6.90$ & $44.80 \pm 9.72$ & \\
\hline & & After & $42.30 \pm 13.26$ & $35.67 \pm 7.84$ & $42.20 \pm 8.65$ & \\
\hline
\end{tabular}

* Statistically significant at $\mathrm{p}<0.05$

To analyze feet, the percentage of each foot strike segment, from heel contact to foot flat, from foot flat to heel off, and from heel off to toe off, during the stance phase was analyzed.

Exercises were conducted in a physical therapy exercise room. The exercise routine consisted of 10 minutes of warmup exercises, 40 minutes of main exercises, and 10 minutes of cool down, for a total of 60 minutes. Exercise was done 5 times a week for 4 weeks. The superficial muscle exercise and deep muscle exercise programs were based on a program by Kim et $\mathrm{al}^{5}$. The superficial and deep trunk muscle exercise programs had 10 main exercises. Three sets of each exercise were performed, with 30 seconds of rest between each set.

Data were analyzed using SPSS 21.0 (SPSS, Chicago, IL, USA) statistical software. The average and standard deviation of the participants' general characteristics were calculated. A one-way ANOVA was conducted to compare results between each group. A paired t-test was conducted to compare the before and after results within each group. The statistical significance level was set at $\alpha=0.05$.

\section{RESULTS}

In Table 1, we present the results of the CG, SMEG, and DMEG groups on gait.

In the CG, SMEG, and DMEG groups, there were no significant differences between the before and after values for foot length, foot width, toe angle, step time, step length, heel contact to foot flat, foot flat to heel off, and heel off to toe off $(\mathrm{p}>0.05)$.

There were no significant differences between the values of each group for foot length, foot width, toe angle, step time and step length $(\mathrm{p}>0.05)$.

Next, there were no significant differences between the before values of each group from heel contact to foot flat, foot flat to heel off, and heel off to toe off ( $p>0.05)$.

However, the after values from right heel contact to foot flat, left foot flat to heel off, right foot flat to heel off, and left heel off to toe off significantly differed between groups $(p<0.05)$. However, the after values of left heel contact to foot flat and right heel off to toe off did not significantly differ between groups $(\mathrm{p}>0.05)$. 


\section{DISCUSSION}

This study examined the effects of superficial muscle and deep muscle exercise on gait by differentiating the trunk muscles.

Trunk muscle exercises contribute to the stability of the trunk, maintain balance with the core muscle, and increase postural stability through nerve root training ${ }^{10,11)}$.

In the current study, analysis of the time ratio from foot flat to heel off showed that the time ratio of the SMEG group increased while that of the DMEG group decreased compared with that of the CG group, which indicated that when the superficial muscles are exercised, the time of mild stance becomes longer during gait, resulting in more stability during gait.

However, to examine the time ratio from heel contact to foot flat and that from heel off to toe off, the time ratio of SMEG decreased and that of DMEG increased compared to that of CG. When the deep muscles of the trunk were exercised, the time of foot flat during heel contact and the time of toe off during heel off became longer, which indicates that the mobility of the feet during gait increased.

Brill \& Couzen ${ }^{12)}$ noted that when holding a heavy object, the large muscles of the trunk contracted simultaneously, and this played a role in holding the object more safely. In addition, this simultaneous contraction of large muscles increased the stability of the spine. These results are considered to be associated with the results of the current study, where the superficial muscles were activated, increasing the time of mid stance.

According to Suzy et al. ${ }^{5)}$, when deep trunk muscle exercises were performed, the foot pressure of the toe side, the lateral side, and the heels increased. This is considered to be associated with the results of this study, where the time of foot flat became longer during heel contact and the time of toe off became longer during heel off.
Therefore, it is important to focus on the muscle that would increase stability and mobility during core exercises or trunk stabilization exercises.

This study applied trunk muscle exercises by differentiating the muscles into the superficial trunk muscle and the deep trunk muscle. According to the results, the superficial trunk muscle exercises improved stability during mid stance in gait. The deep trunk muscle exercises improved mobility during heel contact to foot flat and heel off to toe off in gait.

\section{REFERENCES}

1) $\mathrm{Kim} \mathrm{CY}$, Cho $\mathrm{SH}$ : Review on the role of core stability and core exercise program in postural control. JKSHS, 2013, 10: 53-68.

2) Kisner C, Colby LA: Therapeutic exercise: foundations and techniques, 5th ed. FA Davis, 2007.

3) Hodges PW: Core stability exercise in chronic low back pain. Orthop Clin North Am, 2003, 34: 245-254. [Medline] [CrossRef]

4) Magee DJ: Instability and stabilization. Theoryand treatment, 2nd ed. Seminar Workbook, 1999.

5) Kim S, Shim J, Kim S, et al.: The effect of superficial trunk muscle exercise and deep trunk muscle exercise on the foot pressure of healthy adults. J Phys Ther Sci, 2015, 27: 711-713. [Medline] [CrossRef]

6) Akuthota V, Nadler SF: Core strengthening. Arch Phys Med Rehabil, 2004, 85: S86-S92. [Medline] [CrossRef]

7) Bjerkefors A, Ekblom MM, Josefsson K, et al.: Deep and superficial abdominal muscle activation during trunk stabilization exercises with and without instruction to hollow. Man Ther, 2010, 15: 502-507. [Medline] [CrossRef]

8) Hase K, Stein RB: Turning strategies during human walking. J Neurophysiol, 1999, 81: 2914-2922. [Medline]

9) Shim JM: Comparison of gait and feet during Nordic pole walking and unassisted walking on a treadmill. J Phys Ther Sci, 2012, 24: 1225-1228. [CrossRef]

10) Seidler RD, Martin PE: The effects of short term balance training on the postural control of older adults. Gait Posture, 1997, 6: 224-236. [CrossRef]

11) Krabak B, Kennedy DJ: Functional rehabilitation of lumbar spine injuries in the athlete. Sports Med Arthrosc Rev, 2008, 16: 47-54. [Medline] [CrossRef]

12) Brill PW, Couzen GS: The Core Program, 1st ed. New York: Bantam Books, 2002. 